\title{
The SCAR READER Project: Toward a High-Quality Database of Mean Antarctic Meteorological Observations
}

\author{
John Turner,* Steve R. Colwell,* Gareth J. Marshall,* Tom A. Lachlan-Cope,* \\ Andrew M. Carleton, ${ }^{+}$Phil D. Jones, ${ }^{*}$ Victor Lagun, ${ }^{\circledR}$ Phil A. Reid, \& And Svetlana Iagovkina** \\ *British Antarctic Survey, Natural Environment Research Council, Cambridge, United Kingdom \\ ${ }^{+}$College of Earth and Mineral Sciences, The Pennsylvania State University, University Park, Pennsylvania \\ ${ }^{\#}$ Climatic Research Unit, University of East Anglia, Norwich, United Kingdom \\ ${ }^{@}$ Arctic and Antarctic Research Institute, Saint Petersburg, Russia \\ $\&$ National Climate Centre, Bureau of Meteorology, Melbourne, Victoria, Australia \\ **Department of Dynamical Meteorology, Main Geophysical Observatory, Saint Petersburg, Russia
}

23 April 2003 and 22 December 2003

ABSTRACT

A new dataset of monthly and annual mean near-surface climate data (temperature, surface and mean sea level pressure, and wind speed) for the Antarctic region has been created using historical observations [Scientific Committee on Antarctic Research (SCAR) Reference Antarctic Data for Environmental Research (READER)]. Where possible, 6-hourly surface synoptic and automatic weather station observations were used to compute the means. The ability to quality control the data at the level of individual observations has produced a more accurate series of monthly means than was available previously. At the time of writing, the mean data are available on the Internet (http://www.antarctica.ac.uk/met/programs-hosted.html). Data for 43 surface-staffed stations and 61 automatic weather stations are included in the database. Here, mean temperature, pressure, and wind speed data for 19 occupied stations with long records are provided.

\section{Introduction}

There is currently a high level of interest in climate variability and change in the Antarctic because of the marked warming that has been observed over the Antarctic Peninsula in recent decades, both near the surface and in the free atmosphere (King 1994; King and Harangozo 1998; Vaughan et al. 2001; Marshall et al. 2002), and the disintegration of a number of floating ice shelves in this area (Scambos et al. 2000). At the Faraday (now Vernadsky) station on the western side of the peninsula (see Fig. 1 for places referred to in the text), the annual mean near-surface temperature has risen by about $2.5^{\circ} \mathrm{C}$ since the 1950s, which is as large as any warming observed on Earth over this period (Vaughan et al. 2001). However, the region of marked warming appears to be quite limited (King and Comiso 2003), with the temperature rise at Signy, to the northeast of the tip of the Antarctic Peninsula, being only about one-half of this value (Quayle et al. 2002).

Corresponding author address: John Turner, British Antarctic Survey, Natural Environment Research Council, High Cross, Madingley Road, Cambridge CB3 OET, United Kingdom.

E-mail: j.turner@bas.ac.uk
For the rest of the Antarctic beyond the Antarctic Peninsula, the picture of climate change since instrumental observations began during the 1950s is less clear. However, there have been a number of investigations into the temperature trends at the occupied Antarctic stations. Jacka and Budd (1991) analyzed station data for 1956 to the late 1980s and found that the mean of the slopes of regression lines through the datasets indicated a warming of around $0.28^{\circ} \mathrm{C}(10 \mathrm{yr})^{-1}$; only two stations, Mawson and Molodezhnaya, showed any cooling.

Jones (1995) examined the mean temperature trend at 16 stations on the continent over the period 1957-94 and found an increase of $0.57^{\circ} \mathrm{C}$ over this period, which was statistically significant at the $<5 \%$ level. Jacka and Budd updated their earlier work for the period of 195996 (Jacka and Budd 1991, 1998) and found a warming of $0.12^{\circ} \mathrm{C}(10 \mathrm{yr})^{-1}$, which is comparable to the rate of change reported by Jones (1995).

The Jones (1995) study of continentwide temperature trends has been updated to some degree by Jones and Reid (2001), which is an Internet publication that has not been peer reviewed. Apart from error checking of all of the Jones (1995) data against other sources, the 


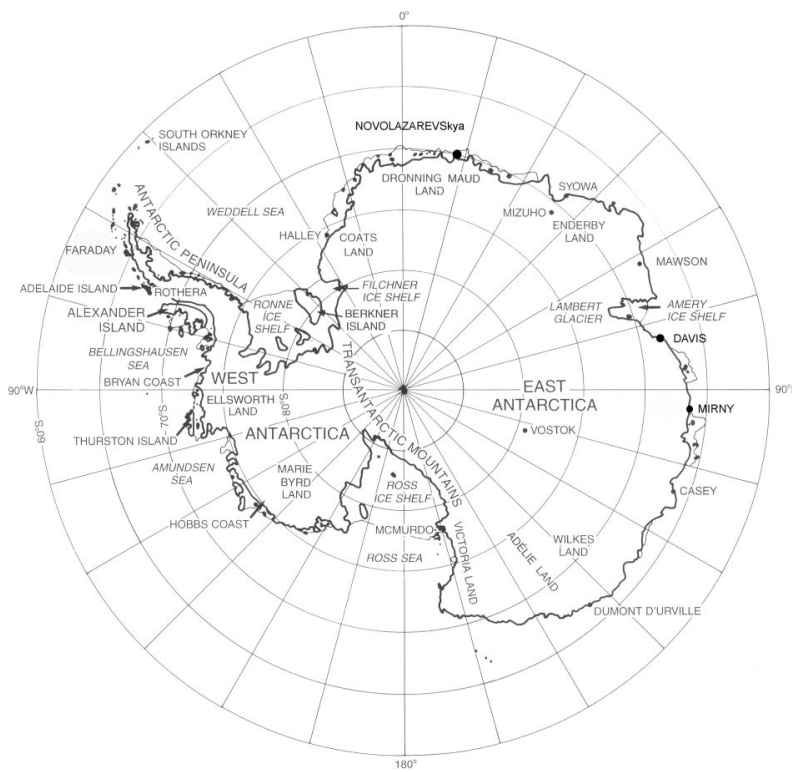

FIG. 1. A map of the Antarctic with locations of a selection of the research stations indicated.

paper presents an examination of continentwide temperature averages based on the Raper et al. (1984) and Jones (1995) studies. The paper also presents an analysis of temperature trends on a monthly basis, makes a brief assessment of the spatial variation in temperature trends, and presents a comparison with changes in atmospheric pressure. The findings, in part, suggest that stations within the same grouping (based on position, e.g., East Antarctica coastal stations or Dronning Maud Land) show similar seasonality to trends. The findings also suggest that these trends may be related in some way to circulation changes, although the relationship is not always clear.

Some studies have attempted to determine whether the Antarctic as a whole has warmed or cooled throughout the instrumental period (Doran et al. 2002; Raper et al. 1984). Raper et al. (1984) calculated the annual mean temperature for the continent by taking an areally weighted mean of all available station data. The annual mean Antarctic temperature was found to have a warming trend of $0.29^{\circ} \mathrm{C}(10 \mathrm{yr})^{-1}$ for $1957-82$, which was significant at the $<5 \%$ level. However, there are so few observations, considering the size of the continent, that it can be argued that it is not meaningful to determine such a quantity using the available in situ observations (Turner et al. 2002).

A major problem in trying to examine Antarctic climate change over the last century has been the lack of a consistent dataset of meteorological observations and climatological means. Over the years, various workers have attempted to bring together the available monthly mean data statistics into databases of Antarctic climate data. Jacka et al. (1984) assembled monthly and annual mean near-surface temperature data for the Antarctic and various island stations across the Southern Ocean and South Pacific. This dataset has been updated periodically and at the time of writing was available on the Internet (http://www.antcrc.utas.edu.au/ jacka/). Schwerdtfeger (1984), in his classic text on the meteorology of the Antarctic, included time series of annual mean temperatures and long-term monthly mean temperatures for a number of stations with long records. Jones and Limbert (1987) produced a comprehensive dataset of monthly and annual mean near-surface air temperature and mean sea level pressure (MSLP) data for 29 stations south of $60^{\circ} \mathrm{S}$. These data were originally published in hard-copy form but have recently been updated by Jones and Reid (2001) and were made available on the Internet. The Goddard Institute for Space Studies also provided tables of monthly mean temperatures for selected Antarctic stations (information made available online at http://www.giss.nasa.gov/).

All the above databases were compiled from monthly mean data supplied by weather services or Antarctic operators, where the averaging of the synoptic reports and the quality control of the data were presumed to have already been carried out. Some further quality control was done on the monthly data (see Jones and Limbert 1987), but this is much more difficult to carry out once the synoptic reports have been averaged.

A further problem in the use of such data is that the mean daily temperatures have been produced in different ways. The method recommended by the World Meteorological Organization (WMO) is to take the mean of the 3- or 6-hourly reports. However, some stations do not make routine observations at this frequency, and so the daily mean temperature is computed as the mean of the maximum and minimum temperatures. A comparison of the mean monthly temperature for Mawson, determined from the maximum-minimum method and from the eight 3-hourly synoptic observations, suggested differences from $0.1^{\circ}$ to $0.2^{\circ} \mathrm{C}$. However, although the WMO does not have a recommended method for determining the daily mean temperature, the main problem with respect to consistency and homogeneity comes from changes in the method applied at particular stations.

In addition, many stations have moved short distances over their period of operation and changed instrumentation, possibly several times. All of these factors make the detection of change in individual station records difficult and complicate the intercomparison of trends on the regional and continental scale.

For these reasons it was decided to produce an improved dataset of Antarctic climate data attempting, where possible, to go back to the original synoptic reports and recompute monthly and annual mean statistics. The database consists of monthly mean near-surface air temperature, MSLP or surface pressure, and 10-m wind speed. In addition, it was decided to include metadata on the changes that have taken place in the observing practices, station locations, and instrumentation, in or- 
der that the possible impact of changes could be examined.

The Reference Antarctic Data for Environmental Research (READER) project is being undertaken by the Scientific Committee on Antarctic Research (SCAR). READER is seen as an ongoing activity in which the online database will be developed and data gaps will be filled as the last few records that are still available only in hard-copy form are digitized and means are recomputed.

For a second phase of the project, upper-air wind speed and temperature, along with geopotential height for selected levels, are also being collected. This is seen as an important part of the project because only a small amount of the upper-air data has previously been available in any of the climate databases for the continent.

In this paper we describe the data that have been collected for the project and the quality control that has been applied, and we present the mean near-surface air temperature, MSLP, and 10-m wind speed data for a selection of the currently available stations.

\section{Data collected}

It is clearly impossible to assemble a perfect dataset of Antarctic observations and climatological means because of the different ways the measurements have been made over the years, the fact that some of the early data have been lost, and the difficulties of locating some of the early meteorological registers and getting them digitized. The approach we have taken within READER has been to recompute the monthly means from the synoptic reports whenever possible, but if these data were not available, then means obtained from other sources were used. So, for each form of data, a preferred order of mean value was created based on our experience of the accuracy of particular forms of data.

\section{a. Selection of stations for inclusion in the READER dataset}

Many stations have operated in the Antarctic for periods of several years, but it is the long, near-continuous records that are of the greatest value for studies of climate variability and change. In assembling the READER dataset the goal was, therefore, not to include all of the short time series of observations that have been collected, but to concentrate on obtaining high-quality data for the longest records available.

To be included in the dataset it was decided that a surface record from an occupied station must extend for at least $25 \mathrm{yr}$, although not necessarily continuously, or be currently in operation and have operated for the last $10 \mathrm{yr}$. We have chosen to include only data from yearround stations, since, although data from some of the summer-only stations are of great value, the records of such stations usually do not cover long periods and tend to have gaps.
It was decided not to carry out any merging of data from different stations in a region, for example, Marguerite Bay and Rothera/Adelaide Island. With cases such as this we have included the two sets of records separately, allowing the user to decide whether the two series could be merged in any way. Where possible, information was added to the metadata about station rebuilds and relocation of the meteorological instruments.

For an automatic weather station (AWS) to be included it must be operating now and have worked for the last $5 \mathrm{yr}$, or for $10 \mathrm{yr}$ at some previous time, not necessarily in a continuous period. The surface synoptic stations and AWSs included in the READER dataset were available online at the time of writing (http:// www.antarctica.ac.uk/met/SCAR_ssg_ps/Stations.doc).

\section{b. Surface synoptic observations from occupied stations}

At Antarctic stations the means by which meteorological data have been collected have changed considerably over the years. Until well into the second half of the twentieth century all observations were made manually, with the only automatic instrumentation being barographs and thermographs. All observations were entered into registers with monthly and annual mean statistics being computed at the stations at the end of the appropriate periods. However, from the 1980s increasing use was made of AWSs, either in remote locations or in close proximity to the stations, with the observing systems replacing the traditional manual instruments and the data being transferred to the station electronically.

Although the type of instrumentation and the observing practices have changed at the stations over the years, the individual synoptic observations remain the most reliable form of data for the computation of means. However, the observing frequency varies depending on the station and has even varied during the lifetime of the stations. Within READER we decided that for surface data to be included in the calculation of a mean it must be within $\pm 1 \mathrm{~h}$ of the nominal time (e.g., 0600 UTC data will range from 0500 to 0700 UTC). Nevertheless, the series of synoptic reports from the stations contain a mix of observations predominantly every 3 or $6 \mathrm{~h}$. Although it is tempting to compute the monthly means from all of the available observations, it was felt that this would not produce a dataset that was consistent between stations. We have, therefore, examined the impact on the annual mean temperature of determining the mean from data collected every $3,6,12$ and 24 h (i.e., 1200 UTC data). The difference when using 6-hourly rather than 3-hourly observations was extremely small (a cold bias of less than $-0.01^{\circ} \mathrm{C}$ ), but increased to -0.09 with 12 -hourly data and was $-0.2^{\circ} \mathrm{C}$ when only one observation per day was used. We therefore decided 


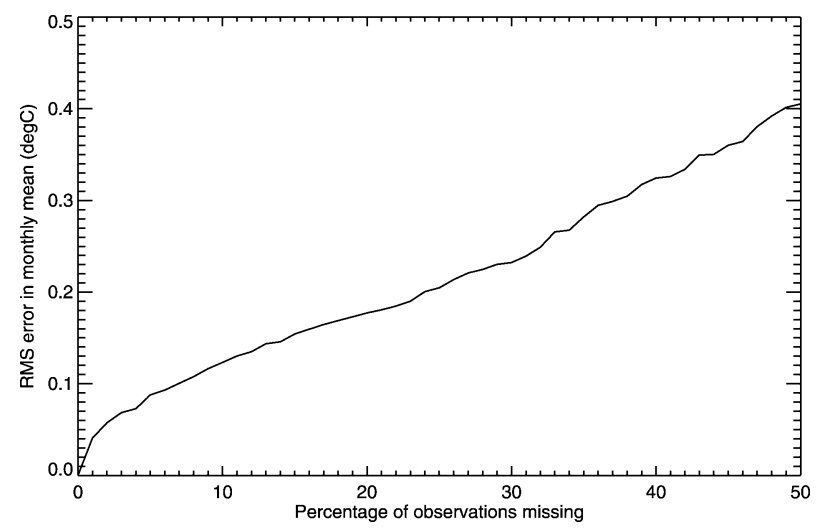

FIG. 2. The rms error in the Faraday monthly mean temperature as a function of the percentage of observations randomly removed from the dataset.

to use 6-hourly surface data throughout the READER project.

A further problem with the data is that a significant percentage of the observations can be missing in a particular month, either distributed singly and randomly throughout the month or with all of the observations missing on consecutive days. The impact of missing data was, therefore, investigated by recomputing the Faraday annual mean temperature with an increasing percentage of the observations (selected randomly from throughout the year) excluded. The results of this experiment are shown in Fig. 2, which indicates that the rms error [computed as indicated in Eq. (1)] increases almost linearly with the amount of data missing. From Fig. 2 it was decided that we should not compute a mean if more than $10 \%$ of the data were missing in any particular month, which would keep the rms error to around $0.1{ }^{\circ} \mathrm{C}$ :

$$
\begin{aligned}
\text { RMS error }=[\text { mean } & \text { (monthly mean } \\
& - \text { mobset } \\
& \text { monthly mean } \left.\left.\text { all }_{\text {all }}\right)^{2}\right]^{-2} .
\end{aligned}
$$

The effects of having data missing for a number of successive days was investigated by recomputing the annual mean Faraday temperature with an increasing number of blocks of data removed. The results of this experiment are shown in Fig. 3. Again, the rms error in the monthly mean temperature increased almost linearly as the number of consecutive days of data that were removed. With the results shown in Fig. 3, it was decided that the monthly mean temperature would only be computed from the synoptic data if there was no block of data extending for 2 days or more. This decision should keep the rms error to within $0.15^{\circ} \mathrm{C}$.

Taking into account the above considerations regarding availability of synoptic observations, the monthly mean data for a particular station were included in the READER dataset in the following priority order:

1) A mean of the 6-hourly synoptic observations is computed, provided that $90 \%$ of the data were available and there were no gaps of more than two consecutive days. In addition, there must be no more than $50 \%$ of the missing values from one time period (0600, 1200 UTC, etc). The synoptic observations were obtained from the Antarctic operators.

2) A "CLIMAT" message is taken off of the Global Telecommunications System (GTS), obtained from

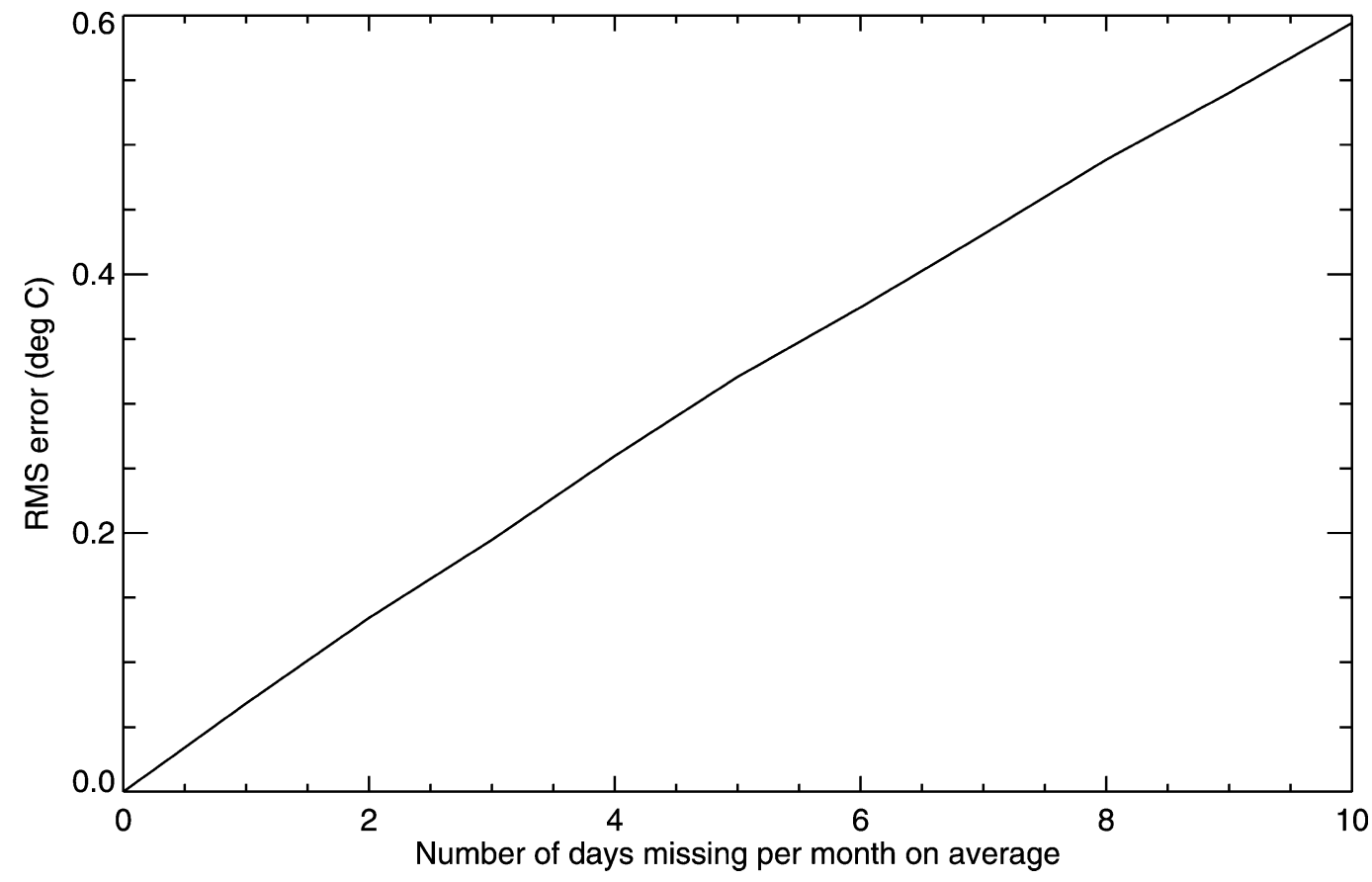

FIG. 3. The rms error in the Faraday monthly mean temperature as a function of removing a number of consecutive days of observations. 
an operator or from Jones and Reid (2001). The CLIMAT messages are usually calculated at the stations at the end of each month and so should be of high quality. However, errors can occur in the computation of the message, or it may become corrupted during transmission. Therefore, option 1 is preferred because the individual synoptic reports can be quality controlled more rigorously. The Jones and Reid (2001) dataset consists largely of CLIMAT messages, and these data were used when synoptic observations were not available. Recent CLIMAT messages were checked against means computed from GTS data when they were available, as a further quality-control measure.

3) Data are derived from synoptic reports off of the GTS. To be included there should be at least $90 \%$ of the reports available and no gaps of more than two consecutive days. No more than $50 \%$ of the missing values should be from one time period. $\mathrm{Ob}-$ servations on the GTS can be in error for a number of telecommunications-related reasons and will not have been subjected to quality control applied by the national operators. However, some basic quality control has been carried out on the GTS data at the British Antarctic Survey.

Temperature, MSLP, and station level pressure are the primary data held in the READER database, but we have also included wind speed but not wind direction. The wind directions recorded at Antarctic stations are often heavily influenced by the local orography and are frequently not representative of the broadscale flow.

\section{c. AWS observations}

Since the 1980s there has been an increasing number of AWSs installed that have filled some of the gaps in the network of occupied stations. The harsh conditions over the Antarctic continent are a difficult environment for which to develop autonomous instrumentation. However, in recent decades a great deal of progress has been made in the development of meteorological instrumentation that can operate unattended for long periods in the Antarctic and transmit the observations out of the Antarctic for insertion onto the GTS.

AWS observations present a number of problems when examining climate change. The sensors tend to be located at $3 \mathrm{~m}$ above the surface when the system is installed, but this height gradually decreases as snow builds up on the surface, which normally results in slightly lower temperatures until the AWS is raised during routine maintenance. Metadata on system maintenance are therefore very valuable when assessing time series of data from AWSs.

Within READER, we have computed the monthly means from the 6-hourly observations obtained from the AWS operators, and the stations included in the dataset were found on the Internet (see section 2a). The
AWSs included were deployed and operated by U.S., Australian, German, and Italian organizations. Many AWS observations are input to the GTS, but the percentage of the possible data that arrives onto the GTS is much lower than for occupied stations because of telecommunications-related problems. The AWS observations on the GTS are generally of lower quality than the data obtained from the system operators because thorough quality control of the data is necessary with systems that are only checked periodically. Within READER we therefore mainly included data from the AWS operators.

As with the surface data from occupied stations, the READER dataset contains tables of monthly means for 0000, 0600, 1200, and 1800 UTC. When they were available, the observations from the principal observing times were used, but if these were not available then data from within $\pm 1 \mathrm{~h}$ of the nominal observing time were used to compute the means.

\section{d. Metadata}

The metadata available for each station clearly depend on the extent to which early records of instrumentation, site location, and so on have survived. However, all stations within the READER dataset have information on the nation(s) operating the station, the WMO number, and whether the data collected were surface only or also upper air. Where possible, details of site moves are included, along with changes in station elevation.

\section{Quality control}

Because READER is based largely on 6-hourly synoptic reports from occupied stations, it was possible to make a thorough assessment of the individual observations before the monthly means were computed. It was found that the errors fell into four main categories:

1) errors that were introduced while the data were being transcribed from the hardcopy registers (e.g., transposition of numbers, missing negative signs),

2) errors that were introduced by electronic problems, including transmission problems on the GTS,

3 ) errors that were introduced by environmental factors, such as anemometers freezing and screens filling with snow, and

4) errors introduced by changes in units (e.g., knots and meters per second) but not recording such changes in the metadata.

In the light of the above, the following checks on the data were made:

1) Erroneous values were eliminated by the data manager manually checking lists of suspect observations flagged by comparing each observation of temperature, pressure, or wind speed with the climatological mean for the month at a particular site and the known 
variability of the parameter at the location. For example, near-surface temperatures from sites in the interior of the Antarctic were flagged if they were above freezing.

2) Physically unrealistic rapid changes in parameters, based on our existing knowledge of synoptic variability at various sites, were also manually checked. A quantity such as surface pressure can change much more rapidly at a coastal site than in the interior, where deep depressions are quite rare, requiring different criteria to be used across the continent. For example, jumps in surface pressure of more than 10 $\mathrm{hPa}(6 \mathrm{~h})^{-1}$, followed by a similar change in the opposite direction, were flagged. Similar 6-h changes of surface temperature $\left(5^{\circ} \mathrm{C}\right)$ and surface wind speed $(40 \mathrm{kt})$ were also flagged.

Data flagged by either of these tests were then checked manually so that the context of the data could be assessed. Many errors were easily corrected, but on a number of occasions it was necessary to go back to the data provider to verify particular observations. If it was not possible to resolve the issue, a null value was entered into the database.

Quality control of data received as monthly means was much more difficult. However, many of these values were taken from Jones and Reid (2001), who, as they report, developed a quality-control scheme that attempted to identify as many errors as possible in the time series.

\section{Accessing the READER dataset}

At the time of writing, the full READER dataset is being disseminated on CD-ROM and through the project's Internet site (online at http://www.antarctica.ac. $\mathrm{uk} / \mathrm{met} /$ programs-hosted.html). The dataset is being kept up to date on a regular basis by inclusion of CLIMAT summaries off of the Internet sites and GTS data. After a period of several years there will be a major qualitycontrol exercise assessing the new data, with the new means being added to the main database.

The monthly mean data are provided as a series of tables, with each mean value also having the percentage of observations used to compute the statistic indicated in brackets. This allows a user to have some indication of the reliability of the data. However, to provide greater flexibility in handling the data, we also include a simple table (without percentages) of the means in text format, which will be easy to manipulate via a spreadsheet.

On the full tables we provide a mean and percentage of observations as long as there is at least one observation. However, no means are provided on the simple tables if there are less than $90 \%$ of the observations. Data in the full tables are color coded to indicate the confidence we have in the mean provided as follows:

1) Black indicates that the statistic was computed from the synoptic observations and that more than $90 \%$ of the observations for the month were available in the surface data.

2) Green is used for means computed from GTS observations.

3) Blue indicates that the mean is a CLIMAT message.

Five sets of monthly mean values are included derived from 0000, 0600, 1200, and 1800 UTC data, and the mean of all four main synoptic hours.

\section{Mean conditions}

In this section we present data for 19 stations that are distributed fairly evenly around the Antarctic and that have long records. The stations are included in the tables in a clockwise order from the Greenwich meridian. Tables 1-3 provide annual and seasonal ${ }^{1}$ mean temperature, MSLP (station pressure for plateau stations), and wind speed data for the 19 stations. In addition, we give the standard deviations for all data. For each station we indicate the period over which the annual means were computed and the primary form of data used.

The temperatures show the extreme range of conditions experienced across the continent. All of the annual and seasonal mean temperatures are negative, except for some of the stations on the Antarctic Peninsula during the summer, with Bellingshausen in the summer being the warmest at $+1.2^{\circ} \mathrm{C}$. Scott Base is the coldest of the coastal stations, with an annual mean temperature of $-19.9^{\circ} \mathrm{C}$. However, temperatures are much colder on the Antarctic Plateau, with South Pole and Vostok having annual mean temperatures of $-49.5^{\circ}$ and $-55.4^{\circ} \mathrm{C}$, respectively. Vostok also has the lowest winter mean temperature at $-66.8^{\circ} \mathrm{C}$.

Faraday/Vernadsky and Rothera have the largest standard deviation in the annual mean temperature $\left(1.6^{\circ} \mathrm{C}\right)$, and this figure arises partly because of the particularly large variability (std dev) of the winter-season temperatures $\left(3.3^{\circ}\right.$ and $\left.3.4^{\circ} \mathrm{C}\right)$ as a result of the stations being close to the sea ice edge (King 1994). However, it should be noted that the large upward trend in the temperature at Faraday noted by King (1994) will have an impact on std dev because the variance of a time series can be expressed as the sum of the variance in the least squares best fit to the data plus the variance of the deviations from this line of best fit. Hence, part of the large temperature std dev at the station will be due to the trend at the location.

The only other station that lies within such close proximity to the ice edge is Marambio, which has the largest std dev of winter temperature at $3.8^{\circ} \mathrm{C}$. At stations such as Faraday, years of extensive (reduced) sea ice cover have significantly colder (warmer) temperatures as a result of the smaller (greater) fluxes of heat from the

\footnotetext{
${ }^{1}$ The seasons are as follows: Summer $=$ December-February, Autumn = March-May, Winter = June-August, and Spring = September-November.
} 
TABLE 1. Annual- and seasonal-mean surface temperatures $\left({ }^{\circ} \mathrm{C}\right)$ and standard deviations (in parentheses) at selected Antarctic stations. The rightmost column indicates the primary source of the data: $\mathrm{S}=$ synoptic observations, $\mathrm{C}=\mathrm{CLIMAT}$ messages, and $\mathrm{G}=\mathrm{GTS}$ data.

\begin{tabular}{|c|c|c|c|c|c|c|c|}
\hline Station & Annual & Spring & Summer & Autumn & Winter & Period & Data used \\
\hline Novolazarevskaya & $-10.3(0.6)$ & $-11.8(1.1)$ & $-1.6(0.8)$ & $-11.1(1.1)$ & $-16.8(1.5)$ & $1962-2000$ & $\mathrm{~S}$ and $\mathrm{C}$ \\
\hline Syowa & $-10.5(0.8)$ & $-12.8(1.2)$ & $-1.8(0.6)$ & $-10.0(1.3)$ & $-17.6(1.6)$ & 1960-61, 1967-2000 & $\mathrm{S}$ \\
\hline Molodezhnaya & $-11.0(0.6)$ & $-12.8(1.0)$ & $-2.1(0.7)$ & $-11.5(1.0)$ & $-17.5(1.5)$ & 1964-95, 1997-98 & $\mathrm{C}$ and $\mathrm{G}$ \\
\hline Mawson & $-11.2(0.8)$ & $-12.0(1.0)$ & $-1.5(0.8)$ & $-13.8(1.4)$ & $-17.7(1.8)$ & $1955-2000$ & $\mathrm{~S}$ and $\mathrm{G}$ \\
\hline Davis & $-10.2(0.9)$ & $-11.1(1.3)$ & $-0.6(0.7)$ & $-12.4(1.8)$ & $-16.6(1.9)$ & $1958-63,1970-2000$ & $\mathrm{~S}$ and $\mathrm{G}$ \\
\hline Mirny & $-11.3(0.8)$ & $-12.5(1.3)$ & $-3.3(0.8)$ & $-13.3(1.5)$ & $-16.4(1.7)$ & $1956-2000$ & $\mathrm{~S}$ and $\mathrm{G}$ \\
\hline Vostok & $-55.4(0.8)$ & $-55.5(1.3)$ & $-36.1(1.0)$ & $-63.1(1.6)$ & $-66.8(2.2)$ & $1958-2000$ & $\mathrm{C}$ and $\mathrm{G}$ \\
\hline Casey & $-9.2(0.9)$ & $-10.4(1.3)$ & $-1.2(0.7)$ & $-11.0(1.8)$ & $-14.4(1.9)$ & $1962-2000$ & $\mathrm{~S}$ and $\mathrm{G}$ \\
\hline Dumont d'Urville & $-10.7(0.7)$ & $-11.9(1.0)$ & $-2.3(0.7)$ & $-12.4(1.2)$ & $-16.4(1.5)$ & $1956-2000$ & $\mathrm{~S}$ and $\mathrm{C}$ \\
\hline Scott Base & $-19.9(1.0)$ & $-20.5(1.9)$ & $-6.9(1.0)$ & $-23.7(1.9)$ & $-28.3(2.0)$ & $1958-2000$ & $\mathrm{~S}$ \\
\hline Rothera & $-4.6(1.6)$ & $-5.9(1.8)$ & $+0.7(0.6)$ & $-3.3(1.6)$ & $-10.2(3.3)$ & $1978-200$ & $\mathrm{~S}$ \\
\hline Faraday/Vernadsky & $-4.0(1.6)$ & $-4.9(1.5)$ & $+0.3(0.7)$ & $-2.7(1.9)$ & $-8.6(3.4)$ & $1951-2000$ & $\mathrm{~S}$ \\
\hline Bellingshausen & $-2.4(0.8)$ & $-2.8(0.9)$ & $+1.2(0.5)$ & $-1.7(1.2)$ & $-6.2(2.0)$ & $1969-2000$ & $\mathrm{~S}$ \\
\hline Esperanza & $-5.2(1.2)$ & $-4.3(1.4)$ & $+0.4(0.9)$ & $-6.2(2.3)$ & $-10.6(2.2)$ & $1961-2000$ & $\mathrm{C}$ \\
\hline Marambio & $-8.4(1.5)$ & $-7.5(1.6)$ & $-2.0(0.9)$ & $-10.1(2.8)$ & $-14.2(3.8)$ & $1971-2000$ & $\mathrm{C}$ \\
\hline Orcadas & $-4.0(1.2)$ & $-3.8(1.4)$ & $+0.3(0.7)$ & $-3.0(1.7)$ & $-9.7(2.6)$ & $1904-2000$ & $\mathrm{C}$ \\
\hline Halley & $-18.7(1.1)$ & $-19.2(1.6)$ & $-6.6(0.8)$ & $-20.9(2.2)$ & $-27.9(2.2)$ & $1957-2000$ & $\mathrm{~S}$ \\
\hline Neumayer & $-16.0(0.7)$ & $-17.0(1.3)$ & $-5.7(0.7)$ & $-17.1(1.3)$ & $-24.0(1.7)$ & 1982-2000 & $\mathrm{S}$ \\
\hline Amundsen-Scott & $-49.5(0.6)$ & $-49.7(1.6)$ & $-32.4(1.4)$ & $-56.6(1.2)$ & $-59.3(1.6)$ & $1958-2000$ & $\mathrm{~S}$ \\
\hline
\end{tabular}

ocean. It is interesting to note that all of the stations in Table 1 except Esperanza have their largest standard deviations during the winter.

The annual mean surface and MSL pressure data in Table 2 are dominated by the circumpolar trough that rings the Antarctic between $60^{\circ}$ and $70^{\circ} \mathrm{S}$. The lowest pressures within the trough are found north of the continent and so are not represented in Table 2. However, the higher pressures to the north and south of the trough are reflected in the data from Orcadas and Scott Base. The data for Vostok and South Pole have not been reduced to mean sea level because of the problems of extrapolation over such great thicknesses.

Table 3 contains comparable annual and seasonal mean 10-m wind speeds for a number of the stations, although lack of data for several sites means that the coverage is not as good as for the temperatures and pressures. The strength of the mean winds is a function of the orography near to the stations and the proximity to the major storm tracks. The stations around the coast of East Antarctica, such as Novolazarevskaya, Mawson, Mirny, and Dumont d'Urville have stronger mean winds than the sites on the Antarctic Peninsula, such as Faraday and Rothera, which occupy more sheltered locations.

Most of the stations have a minimum wind speed during the summer when synoptic-scale low pressure systems are the least active (Jones and Simmonds 1993) and the katabatic winds are at a minimum. The two plateau stations have lower mean wind speeds than most

TABLE 2. Annual- and seasonal-mean MSLP ( $\mathrm{hPa}$ ) (station level pressure for Vostak and Pole) and standard deviations (in parentheses) at selected Antarctic stations. The rightmost column indicates the primary source of the data: $\mathrm{S}=$ synoptic observations, $\mathrm{C}=\mathrm{CLIMAT}$ messages, and $\mathrm{G}=$ GTS data.

\begin{tabular}{|c|c|c|c|c|c|c|c|}
\hline Station & Annual & Spring & Summer & Autumn & Winter & Period & Data used \\
\hline Novolazarevskaya & $987.3(1.7)$ & $984.8(2.8)$ & $989.6(2.9)$ & $986.8(3.4)$ & $987.9(3.1)$ & $1962-2000$ & $\mathrm{~S}$ and $\mathrm{C}$ \\
\hline Syowa & $986.5(1.5)$ & $984.1(2.7)$ & $989.2(2.3)$ & $985.8(3.0)$ & $986.7(2.9)$ & $1960-61,1967-2000$ & S \\
\hline Molodezhnaya & $986.9(1.7)$ & $984.1(2.5)$ & $989.6(2.7)$ & $986.5(3.1)$ & $987.3(3.2)$ & $1964-98$ & $\mathrm{~S}$ and $\mathrm{C}$ \\
\hline Mawson & $988.2(1.5)$ & $985.1(2.4)$ & $989.6(2.3)$ & $990.1(2.5)$ & $989.3(2.9)$ & 1955-2000 & $\mathrm{S}$ and $\mathrm{G}$ \\
\hline Davis & $986.9(1.5)$ & $983.9(2.4)$ & $988.9(2.3)$ & $987.8(2.7)$ & $987.2(2.9)$ & $1958-63,1970-2000$ & $\mathrm{~S}$ and $\mathrm{G}$ \\
\hline Mirny & $986.5(1.9)$ & $983.2(2.6)$ & $988.8(2.6)$ & $987.3(3.0)$ & $986.5(3.6)$ & $1956-2000$ & $\mathrm{~S}$ and $\mathrm{G}$ \\
\hline Vostok & $624.7(1.7)$ & $621.1(2.8)$ & $631.1(3.0)$ & $623.5(3.3)$ & $622.0(3.7)$ & $1958-2000$ & $\mathrm{C}$ and $\mathrm{G}$ \\
\hline Casey & $984.6(1.7)$ & $981.3(2.7)$ & $987.7(2.7)$ & $984.8(3.1)$ & $984.8(3.7)$ & $1962-2000$ & $\mathrm{~S}$ and $\mathrm{G}$ \\
\hline Dumont d'Urville & $988.0(1.7)$ & $984.2(2.5)$ & $989.6(3.1)$ & $987.8(3.1)$ & $990.5(3.4)$ & $1956-2000$ & $\mathrm{~S}$ and $\mathrm{C}$ \\
\hline Scott Base & $990.9(1.6)$ & $986.3(3.0)$ & $993.2(3.0)$ & $992.2(3.3)$ & $991.8(3.9)$ & $1958-2000$ & $\mathrm{C}$ \\
\hline Rothera & $987.6(2.1)$ & $984.7(3.8)$ & $987.4(2.7)$ & $988.7(3.8)$ & $989.4(4.2)$ & $1978-2000$ & $\mathrm{~S}$ \\
\hline Faraday/Vernadsky & $989.6(1.6)$ & $987.1(3.3)$ & $989.6(2.7)$ & $989.9(3.3)$ & $991.7(3.5)$ & $1951-2000$ & $\mathrm{~S}$ \\
\hline Bellinghausen & $991.4(1.6)$ & $989.4(2.8)$ & $990.8(2.6)$ & $992.2(2.8)$ & $993.4(3.5)$ & $1969-2000$ & $\mathrm{~S}$ \\
\hline Esperanza & $989.9(1.8)$ & $987.0(3.2)$ & $989.6(3.1)$ & $990.7(3.0)$ & $992.3(3.5)$ & $1952-2000$ & $\mathrm{C}$ and $\mathrm{G}$ \\
\hline Marambio & $989.7(2.1)$ & $986.4(3.9)$ & $989.3(3.7)$ & $991.7(2.9)$ & $991.5(3.9)$ & $1971-2000$ & $\mathrm{C}$ \\
\hline Orcadas & $992.2(1.4)$ & $991.1(2.9)$ & $991.3(2.4)$ & $991.7(3.0)$ & $994.5(2.5)$ & $1904-2000$ & $\mathrm{C}$ \\
\hline Halley & $988.9(1.6)$ & $985.8(2.8)$ & $991.5(2.9)$ & $988.7(2.8)$ & $989.5(3.0)$ & $1957-2000$ & $\mathrm{~S}$ \\
\hline Neumayer & $986.4(1.8)$ & $984.0(3.8)$ & $988.7(2.6)$ & $986.0(3.0)$ & $986.8(3.1)$ & $1982-2000$ & $\mathrm{~S}$ \\
\hline Amundsen-Scott & $681.3(1.4)$ & $678.3(2.7)$ & $688.1(2.4)$ & $680.7(2.8)$ & $678.1(3.1)$ & $1958-2000$ & $\mathrm{~S}$ \\
\hline
\end{tabular}


TABLE 3. Annual- and seasonal-mean surface wind speed $\left(\mathrm{m} \mathrm{s}^{-1}\right)$ and standard deviations (in parentheses) at selected Antarctic stations. The rightmost column indicates the primary source of the data: $\mathrm{S}=$ synoptic observations, $\mathrm{C}=\mathrm{CLIMAT}$ messages, and $\mathrm{G}=\mathrm{GTS}$ data. Here, N/A indicates "not available."

\begin{tabular}{|c|c|c|c|c|c|c|c|}
\hline Station & Annual & Spring & Summer & Autumn & Winter & Period & Data used \\
\hline Novolazarevskaya & $9.6(0.7)$ & $8.6(1.0)$ & $7.7(1.1)$ & $10.9(1.1)$ & $10.5(1.3)$ & $1962-2000$ & $\mathrm{~S}$ and $\mathrm{C}$ \\
\hline Syowa & $2.3(0.3)$ & $2.3(0.3)$ & $2.3(0.3)$ & $2.3(0.3)$ & $2.3(0.3)$ & $1960-61,1967-2000$ & $\mathrm{~S}$ \\
\hline Molodezhnaya & N/A & N/A & N/A & N/A & N/A & - & - \\
\hline Mawson & $11.0(0.9)$ & $11.1(1.3)$ & $9.5(1.0)$ & $11.3(1.3)$ & $11.8(1.5)$ & $1955-2000$ & $\mathrm{~S}$ and $\mathrm{G}$ \\
\hline Davis & $5.1(0.5)$ & $5.2(0.7)$ & $5.3(0.6)$ & $4.8(0.7)$ & $5.1(0.9)$ & $1958-63,1970-2000$ & $\mathrm{~S}$ and $\mathrm{G}$ \\
\hline Mirny & $11.1(0.7)$ & $11.8(0.7)$ & $8.5(0.7)$ & $12.2(0.9)$ & $12.8(1.3)$ & $1956-2000$ & $S$ and $G$ \\
\hline Vostak & $5.1(0.3)$ & $5.1(0.5)$ & $4.6(0.3)$ & $5.4(0.4)$ & $5.2(0.5)$ & $1958-2000$ & $\mathrm{C}$ and $\mathrm{G}$ \\
\hline Casey & $6.2(0.7)$ & $6.4(1.1)$ & $5.0(0.8)$ & $6.1(1.1)$ & $7.5(1.1)$ & $1962-2000$ & $\mathrm{~S}$ and $\mathrm{G}$ \\
\hline Dumont d'Urville & $9.6(0.8)$ & $9.4(1.1)$ & $9.0(1.1)$ & $10.5(1.4)$ & $9.6(1.0)$ & $1956-2000$ & $\mathrm{~S}$ and $\mathrm{C}$ \\
\hline Scott Base & N/A & N/A & N/A & N/A & N/A & - & - \\
\hline Rothera & $5.7(0.6)$ & $6.5(0.8)$ & $4.7(0.7)$ & $6.0(1.0)$ & $6.2(1.0)$ & $1978-2000$ & S \\
\hline Faraday/Vernadsky & $4.0(0.5)$ & $4.6(0.6)$ & $3.0(0.7)$ & $4.0(0.8)$ & $4.2(0.8)$ & $1951-2000$ & $\mathrm{~S}$ \\
\hline Bellingshausen & $7.2(0.5)$ & $7.6(0.7)$ & $6.6(0.5)$ & $7.3(0.7)$ & $7.6(0.7)$ & 1969-2000 & $\mathrm{S}$ \\
\hline Esperanza & N/A & N/A & N/A & N/A & N/A & - & - \\
\hline Marambio & N/A & N/A & N/A & N/A & N/A & 一 & - \\
\hline Orcadas & N/A & N/A & N/A & N/A & N/A & - & - \\
\hline Halley & $6.5(0.7)$ & $7.0(1.0)$ & $5.5(0.7)$ & $6.6(1.1)$ & $6.7(1.0)$ & $1957-2000$ & $\mathrm{~S}$ \\
\hline Neumayer & $8.9(0.5)$ & $9.4(1.0)$ & $7.1(1.0)$ & $9.6(0.7)$ & $8.6(1.2)$ & $1982-2000$ & $\mathrm{~S}$ \\
\hline Amundsen-Scott & $5.3(0.7)$ & $5.6(0.8)$ & $4.2(0.5)$ & $5.5(0.8)$ & $5.9(1.0)$ & $1958-2000$ & $\mathrm{~S}$ \\
\hline
\end{tabular}

of the coastal stations, but still have mean speeds of about $5 \mathrm{~m} \mathrm{~s}^{-1}$ for the year.

\section{Discussion and future work}

The first phase of the READER project has produced a new dataset of surface climate data for the Antarctic that has been thoroughly quality controlled and that provides a good basis for investigations of climate variability and change for the instrumental period.

This paper has described the results of the first phase of READER, but the project is still ongoing. Data from a number of the stations are still being digitized from the original meteorological registers and means computed from these observations will be added to the dataset.

The next phase of the project will be to complete the digitization of the Russian upper-air data. The Russian stations provide some of the longest upper-air records in the Antarctic, and it will be particularly valuable for studies of climate variability and change to have the monthly means rederived from the original ascents. The READER dataset is also being routinely updated with the latest CLIMAT messages off of the GTS. Periodically, the latest observations will be obtained from the various nations and the dataset will be updated with new means derived from the synoptic data.

The READER project has produced a new dataset of Antarctic climate means based, whenever possible, on the routine synoptic reports that have been subject to a thorough quality-control procedure. While it will never be possible to produce the perfect Antarctic climate dataset, we believe that the READER dataset is an improvement over early records that will aid those concerned with Antarctic climate investigations.
Acknowledgments. The authors are grateful to the Scientific Committee on Antarctic Research for supporting the digitization of some of the early meteorological observations and for funding a workshop on analysis of the READER results. We also thank the many members of the Antarctic meteorological community for providing their synoptic observations.

\section{REFERENCES}

Doran, P. T., and Coauthors, 2002: Antarctic climate cooling and terrestrial ecosystem response. Nature, 415, 517-520.

Jacka, T. H., and W. F. Budd, 1991: Detection of temperature and sea ice extent changes in the Antarctic and Southern Ocean. Proc. Int. Conf. on the Role of the Polar Regions in Global Change, Fairbanks, AK, University of Alaska, Geophysical Institute, 6370.

, and -1998 : Detection of temperature and sea-ice-extent changes in the Antarctic and Southern Ocean, 1949-96. Ann. Glaciol., 27, 553-559.

—_, L. Christou, and B. J. Cook, 1984: A data bank of mean monthly and annual surface temperatures for Antarctica, the Southern Ocean and South Pacific Ocean. Australian National Antarctic Research Expeditions Research Note 22, 98 pp.

Jones, D. A., and I. Simmonds, 1993: A climatology of Southern Hemisphere extratropical cyclones. Climate Dyn., 9, 131-145.

Jones, P. D., 1995: Recent variations in mean temperature and the diurnal temperature range in the Antarctic. Geophys. Res. Lett., 22, 1345-1348.

— temperature and pressure data. Department of Energy Office of Energy Research Rep. TR038, 52 pp.

- and P. A. Reid, cited 2001: A databank of Antarctic surface temperature and pressure data. Carbon Dioxide Information Analysis Center, Oak Ridge National Laboratory, U.S. Department of Energy Rep. ORNL/CDIAC-27, NDP-032. [Available online at http://cdiac.esd.ornl.gov/epubs/ndp/ndp032/ndp032. html.]

King, J. C., 1994: Recent climate variability in the vicinity of the Antarctic Peninsula. Int. J. Climatol., 14, 357-369. 
- and S. A. Harangozo, 1998: Climate change in the western Antarctic Peninsula since 1945: Observations and possible causes. Ann. Glaciol., 27, 571-575.

__ , and J. C. Comiso, 2003: The spatial coherence of interannual temperature variations in the Antarctic Peninsula. Geophys. Res. Lett., 30, 1040, doi:10.1029/2002GL015580.

Marshall, G. J., V. Lagun, and T. A. Lachlan-Cope, 2002: Changes in Antarctic Peninsula tropospheric temperatures from 1956-99: A synthesis of observations and reanalysis data. Int. J. Climatol., 22, 291-310.

Quayle, W. C., L. S. Peck, H. Peat, J. C. Ellis-Evans, and P. R. Harrigan, 2002: Extreme responses to climate change in Antarctic lakes. Science, 295, 645.
Raper, S. C. B., T. M. L. Wigley, P. D. Mayes, P. D. Jones, and M. J. Salinger, 1984: Variations in surface air temperatures. Part 3: The Antarctic, 1957-82. Mon. Wea. Rev. 112, 1341-1353.

Scambos, T., C. Huble, M. Fahnestock, and J. Bohlander, 2000: The link between climate warming and break-up of ice shelves in the Antarctic Peninsula. J. Glaciol., 46, 516-530.

Schwerdtfeger, W., 1984: Weather and Climate of the Antarctic. Elsevier, $261 \mathrm{pp}$.

Turner, J., J. C. King, T. A. Lachlan-Cope, and P. D. Jones, 2002 : Recent temperature trends in the Antarctic. Nature, 418, 291292.

Vaughan, D. G., G. J. Marshall, W. M. Connolley, J. C. King, and R. Mulvaney, 2001: Climate change-Devil in the detail. Science, 293, 1777-1779. 